\title{
HUBUNGAN MOTIVASI IBU MEMBERIKAN ASI EKSKLUSIF DENGAN TEKNIK MENYUSUI YANG BENAR DI PUSKESMAS TEGALREJO YOGYAKARTA
}

(Correlation Of Mother Motivation In Giving Exclusive Breastfeeding Through The Right Technique Of Giving

Breastfeeding Of Puskesmas Tegalrejo Yogyakarta)

Wulan Wijaya ${ }^{1}$, Sudarti ${ }^{2}$, Sri Panuntun ${ }^{3}$

Program studi Diploma IV Bidan Pendidik Fakultas IImu Kesehatan

Universitas Respati Yogyakarta

Email:WulanWijaya013@gmail.com

\begin{abstract}
ABSTRAK
ASI Eksklusif merupakan salah satu program yang cukup sulit dikembangkan karena berkaitan dengan berbagai permasalahan sosial di masyarakat. Pemberian ASI eksklusif pada bayi sering dikaitkan dengan motivasi ibu. Dukungan atau dorongan sangat penting untuk mendukung ibu agar berhasil menyusui dengan benar dan secara eksklusif. Salah satu ketidakberhasilan ibu menyusui anaknya, diantaranya ibu belum memahami sepenuhnya cara menyusui yang benar termasuk teknik menyusui yang benar. Penelitian ini menggunakan deskriptif analitik dengan desain penelitian cross sectional. Teknik pengambilan sampel menggunakan accidental sampling dengan jumlah sampel penelitian sebanyak 36 ibu yang melahirkan atau ibu postpartum. Penelitian yang didaptkan bahwa ada hubungan motivasi ibu memberikan ASI eksklusif dengan teknik menyusui yang benar dengan nilai p-value sebesar 0,001 sedangkan untuk koefisien kontingestinya sebesar

0,513 yang menyatakan tingkat hubungannya sedang antara motivasi ibu memberikan ASI eksklusif dengan teknik menyusui yang benar. Lanjutkan penelitian dengan variable lain seperti dukungan pemberian AS eksklusif terhadap praktik menyusui.
\end{abstract}

\section{Kata Kunci : Teknik menyusui yang benar, motivasi memberikan ASI eksklusif}

\section{ABSTRACT}

Exclusive ASI is one program that is quite difficult to develop because it is related to various social problems in the community. Exclusive breastfeeding in infants is often associated with maternal motivation. Support or encouragement is very important to support mothers to successfully breastfeed correctly and exclusively. One of the unsuccessful mothers breastfeeding their children, including mothers do not fully understand the correct way of breastfeeding, including the correct breastfeeding technique. This study uses descriptive analytic with cross sectional research design. The sampling technique uses accidental sampling with a total sample of 36 mothers giving birth or postpartum mothers. The research found that there was a relationship between the motivation of mothers to give exclusive breastfeeding with the correct breastfeeding technique with a p-value of 0.0001 while for the contingency coefficient of 0.513 which states that the level of the relationship is between the motivation of the mother to give exclusive breastfeeding and the correct breastfeeding technique. Continue research with other variables such as the support of exclusive US giving to breastfeeding practices.

\section{Keyword: The right technique of giving breastfeeding, the motivation of giving exclusive breastfeeding \\ PENDAHULUAN \\ Dalam kehidupan sehari-hari kita sering menemukan ibu-ibu yang tidak berhasil menyusui bayinya atau bahkan menghentikan menyusui \\ bayinya lebih dini dengan berbagai alasan. ibu- ibu yang mengatakan produksi ASI-nya kurang, padahal sebenarnya mereka mempunyai cukup ASI, tetapi kurang mendapat informasi tentang}


manajemen laktasi yang benar, posisi menyusui yang tepat, serta terpengaruh mitos-mitos tentang menyusui, yang umumnya dapat menghambat pemberian ASI. Bayi yang kurang mendapatkan ASI atau kurang minum, pada umumnya bukan karena ibunya yang tidak memproduksi ASI sebanyak yang diperlukan oleh bayi, disebabkan oleh beberapa faktor salah satunya karena posisi menyusui yang tidak benar (Roesli, 2000).

Menurut penelitian Susanti (2006), ada hubungan teknik menyusui dengan produksi ASI pada ibu postpartum primigravida. Hasil yang didapat teknik menyusui buruk 19 orang $(59,38$ $\%)$, teknik menyusui baik 13 orang (40,62 \%). Teknik menyusui berpengaruh pada produksi ASI yang berarti bahwa ibu yang memiliki teknik menyusui buruk cenderung memperoleh produksi ASI yang buruk. Menyusui adalah sesuatu yang alami, dan segala sesuatu yang alami adalah yang terbaik bagi semua orang.

Berdasarkan hasil Survey Demografi Kesehatan Indonesia (SDKI) tahun 2007, bayi yang berumur dibawah lima tahun yang mendapatkan ASI Eksklusif selama enam bulan sebesar $32 \%$. Dengan adanya persentase pemberian ASI Eksklusif pada SDKI tahun 2007, dapat berpengaruh terhadap kualitas sumber daya manusia pada masa yang akan datang yang berdampak pada status kesehatan masyarakat, dimana dapat memungkinkan terjadinya peningkatan angka kesakitan dan kematian pada bayi.

Penelitian dari Septiana (2010), ada hubungan karakteristik ibu menyusui dengan motivasi memberikan ASI Eksklusif. Hasil yang didapat, motivasi memberikan ASI pada ibu nifas termasuk dalam kategori cukup (56,6\%). Petugas kesehatan hendaknya memberikan penyuluhan mengenai ASI Eksklusif, dukungan serta dorongan kepada ibu-ibu untuk meningkatkan pemberian ASI serta motivasi di dalam memberikan ASI Eksklusif. Jika motivasi seorang ibu tinggi dalam memberikan ASI Eksklusif maka harapannya teknik menyusui ibu juga benar, sehingga keinginan ibu untuk terus menyusui bayinya sampai umur enam bulan akan terlaksana.

Berdasarkan studi pendahuluan yang dilakukan oleh peneliti di Puskesmas

Tegalrejo Yogyakarta dari bulan Januari sampai November 2011 terdapat 473 ibu postpartum yang menyusui. Setiap ibu postpartum yang ada di puskesmas Tegalrejo mempunyai motivasi untuk tetap memberikan ASI Eksklusif kepada bayinya sampai umur enam bulan. Tetapi tidak semua motivasi ibu menyusui tersebut bisa terlaksana, hal ini disebabkan karena ada beberapa ibu yang belum benar dalam teknik menyusui. Terdapat enam ibu postpartum yang ada pada saat dilakukan studi pendahuluan. Dari ke enam ibu postpartum tersebut hanya dua ibu postpartum saja yang menyusui bayinya dengan benar sementara empat ibu lainnya belum menyusui secara benar. Ibu yang belum menyusui dengan benar tersebut memiliki pendidikan SMP, bekerja dan anak pertama, meskipun sudah diberikan motivasi dan diajarkan bagaimana cara menyusui yang benar oleh petugas kesehatan.

Berdasarkan uraian diatas, maka peneliti tertarik mengangkat penelitian tentang hubungan motivasi ibu memberikan asi eksklusif dengan teknik menyusui yang benar di Puskesmas Tegalrejo Yogyakarta.

\section{METODE PENELTIAN}

Penelitian ini menggunakan metode deskriptif analitik dengan desain cross sectional karena peneliti bertujuan untuk mengetahui hubungan motivasi ibu memberikan ASI eksklusif dengan teknik menyusui yang benar. Penelitian ini menggunakan pendekatan cross sectional karena peneliti bermaksud melakukan pengukuran atau pengamatan pada saat bersamaaan. Penelitian ini mengukur motivasi ibu memberikan ASI Eksklusif dengan teknik menyusui yang benar dalam waktu bersamaan.

Pada penelitian ini peneliti menggunakan teknik pengambilan sampel accidental sampling. Accidental sampling yaitu siapa saja yang pada saat penelitian berlangsung bertemu dengan peneliti dapat digunakan sebagai sampel, yang memenuhi kriteria inklusi yaitu ibu yang melahirkan normal dan ibu yang bersedia menjadi responden.

Jumlah responden yang diambil peneliti pada saat penelitian berjumlah 36 ibu yang melahirkan, sesuai dengan rumus perkiraan sampel yang dibuat oleh peneliti sebelumnya. 


\begin{tabular}{|c|c|c|c|}
\hline \multicolumn{4}{|c|}{$\begin{array}{l}\begin{array}{l}\text { Distribusi } \\
(n=36)\end{array} \\
\end{array}$} \\
\hline No & Umur & $\mathbf{n}$ & Persentase \\
\hline 1 & $<20$ & 1 & $2.8 \%$ \\
\hline 2 & $20-35$ & 31 & $86.1 \%$ \\
\hline \multirow[t]{2}{*}{3} & $<35$ & 4 & $11.1 \%$ \\
\hline & Total & 36 & $100.0 \%$ \\
\hline No & Pendidikan & $\mathbf{n}$ & Persensate \\
\hline 1 & SD & 2 & $5.6 \%$ \\
\hline 2 & SMP & 10 & $27.8 \%$ \\
\hline 3 & SMA & 23 & $63.9 \%$ \\
\hline \multirow[t]{2}{*}{4} & Diploma/PT & 1 & $2.8 \%$ \\
\hline & Total & 36 & $100.0 \%$ \\
\hline No & Pekerjaan & $\mathrm{n}$ & Persentase \\
\hline 1 & Tidak bekerja & 16 & $44.4 \%$ \\
\hline \multirow[t]{2}{*}{2} & Bekerja & 20 & $55.6 \%$ \\
\hline & Total & 36 & $100.0 \%$ \\
\hline No & Paritas & $\mathbf{n}$ & Persentase \\
\hline 1 & 1 & 20 & 55.5 \\
\hline 2 & 2 & 8 & 22.2 \\
\hline 3 & 3 & 6 & 16.7 \\
\hline \multirow[t]{2}{*}{4} & 4 & 2 & 5.6 \\
\hline & Total & 36 & $100.0 \%$ \\
\hline
\end{tabular}

Sumber: Data Primer

Hasil penelitian menunjukkan karakteristik ibu yang menjadi responden mayoritas berumur 20-35 tahun, yaitu sebanyak 31 responden atau sebanyak $86,1 \%$. untuk ibu yang menjadi responden mayoritas mempunyai pendidikan SMA, yaitu berjumlah 23 responden atau sebanyak $63.9 \%$. Sementara mayoritas responden bekerja, yaitu sebanyak 20 responden atau

$55.6 \%$. Sedangkan untuk paritas mayoritas responden melahirkan anak pertama, yaitu berjumlah 20 responden atau $55.5 \%$.

Ibu yang menjadi responden mayoritas mempunyai motivasi yang tinggi, yaitu sebanyak 21 responden, atau sebanyak $58.3 \%$, sedangkan untuk ibu yang mempunyai motivasi rendah, yaitu sebanyak 15 responden atau $41.7 \%$.
Table 2. Teknik Menyusui Yang Benar di Puskesmas Tegalrejo Yogyakarta

\begin{tabular}{llrr}
\hline No & $\begin{array}{l}\text { Teknik Menyusui Yang } \\
\text { Benar }\end{array}$ & n & Persentase \\
\hline 1 & Tidak Benar & 14 & $38.9 \%$ \\
2 & Benar & 22 & $61.1 \%$ \\
& Total & 36 & $100.0 \%$ \\
\hline
\end{tabular}

Berdasarkan table 2, menunjukkan bahwa $61.1 \%$ atau 22 ibu yang menjadi responden memiliki teknik menyusui yang benar. Sedangkan $38.9 \%$ responden atau sebanyak 14 responden memiliki teknik menyusui yang tidak benar.

Table 3. Hubungan Motivasi Ibu Memberikan ASI Eksklusif dengan Teknik Menyusui Yang benar di Puskesmas Tegalrejo Yogyakarta

\begin{tabular}{|c|c|c|c|c|c|c|c|c|c|}
\hline \multicolumn{10}{|c|}{ Teknik menyusui yang benar } \\
\hline & & \multicolumn{2}{|c|}{ benar } & \multicolumn{2}{|c|}{$\begin{array}{l}\text { Tidak } \\
\text { benar }\end{array}$} & \multicolumn{2}{|c|}{ total } & \multirow[t]{2}{*}{$p$} & \multirow[t]{2}{*}{$\begin{array}{l}Y^{2} \\
\text { hitung }\end{array}$} \\
\hline & & $\mathrm{n}$ & $\%$ & $\mathrm{n}$ & $\%$ & $\mathrm{n}$ & $\%$ & & \\
\hline \multirow{3}{*}{$\begin{array}{l}\text { Motivasi ibu } \\
\text { memberikan } \\
\text { ASI } \\
\text { eksklusif }\end{array}$} & Rendah & 4 & 11.1 & 11 & 30.6 & 15 & 41.7 & \multirow[t]{3}{*}{$\begin{array}{l}0.0 \\
01\end{array}$} & \multirow[t]{3}{*}{12.8} \\
\hline & tinggi & $\begin{array}{l}1 \\
8\end{array}$ & 50 & 3 & 8.3 & 21 & 58.3 & & \\
\hline & Total & $\begin{array}{l}2 \\
2\end{array}$ & 61.1 & 14 & 38.9 & 36 & 100 & & \\
\hline
\end{tabular}

\section{Sumber: Data Primer}

Berdasarkan tabel diatas di dapat bahwa ibu yang memiliki motivasi tinggi dalam memberikan ASI eksklusif dan mempunyai teknik menyusui yang benar sebanyak 18 responden atau $50.0 \%$, sementara ibu dengan motivasi rendah dalam memberikan ASI eksklusif dan mempunyai teknik menyusui yang tidak benar sebanyak 11 responden atau $30.6 \%$.

\begin{tabular}{lllr}
\hline No & $\begin{array}{l}\text { Motivasi lbu } \\
\text { Memberikan ASI }\end{array}$ & $\mathbf{n}$ & Persentase \\
& Eksklusif & & \\
\hline 1 & Rendah & 15 & $41.7 \%$ \\
2 & Tinggi & 21 & $58.3 \%$ \\
& Total & 36 & $100.0 \%$ \\
\hline
\end{tabular}


Hasil analisis chi square (0.001) dan x2 hitung (12.8). Hal ini menunjukkan ada hubungan motivasi ibu memberikan ASI eksklusif dengan teknik menyusui yang benar karena $p$-value $(0.001)<0,05$ dan x2 hitung $(12.8)>$ x2 tabel (10.9). Sedangkan koefisien kontingesti (C) dari hasil uji chi square sebesar 0.513. Berdasarkan hasil diatas Interpretasi koefisien kontingesti (C), interval koefisen 0.513 berada dalam tingkat hubungan sedang. Sehingga disimpulkan bahwa korelasi motivasi ibu memberikan ASI eksklusif dengan teknik menyusui yang benar sebesar 0.513 mempunyai keeratan hubungan yang sedang.

\section{KESIMPULAN}

Dari hasil analisis data dan pembahasan maka peneliti dapat membuat beberapa kesimpulan, antara lain: Karakteristik responden di Puskesmas Tegalrejo Yogyakarta, yaitu: mayoritas ibu berumur $20-35(86,1 \%)$, mayoritas ibu mempunyai tingkat pendidikan SMA $(63,9 \%)$, mayoritas ibu bekerja $(55,6 \%)$, mayoritas paritas ibu anak pertama $(55,5 \%)$. Motivasi ibu memberikan ASI eksklusif mayoritas kategori tinggi $(58,3 \%)$. Teknik menyusui ibu mayoritas kategori benar $(61,1 \%)$. Ibu menyusui dengan motivasi memberikan ASI eksklusif tinggi $(50,0 \%)$ mayoritas mempunyai teknik menyusui yang benar. Hasil analisi uji chi square sebesar 0,001 sedangkan koefisien kontingestinya 0,513 yang bearti ada hubungan motivasi ibu memberikan ASI eksklusif dengan teknik menyusui yang benar dengan tingkat hubungannya sedang.

\section{DAFTAR PUSTAKA}

Ahmad, S. (2009). Panduan Penilaian Ketrampilan. Jakarta: Rajawali Pers

Anonim. (2001). Internet. World Health Organization Exclusive breastfeeding. http://www.who.int/nutrition/topics/exclusiv e_breastfeeding/en/. (Diakses 27 November 2011).

Anonim. (2009).

Internet.

Breastmilk_composition.

http://www.clubnutricia.co.id. (Diakses 29 November 2011).

Arikunto, S. (2010). Prosedur Penelitian Suatu Pendekatan Praktik Edisi Revisi. Jakarta: Rineka Cipta.

DinKes Provinsi DIY. (2011). Profil kesehatan Provinsi DIY

Direktorat Jenderal Bina Kesehatan Masyarakat. (2007). Pelatihan konseling Menyusui:
Panduan Peserta, Jakarta: Departemen kesehatan RI.

Departement Pendidikan Nasional RI. (2003). Sistem Pendidikan Nasional. Jakarta: Departement Pendidikan.

Green, W, L. (1995). Prevention and Health Education in Clinical, School, and

Community Setting. USA: Appleton lange A. Simone Schuter.

Hamzah, U. (2008). Teori Motivasi dan pengukurannya. Jakarta: Bumi Aksara.

Hastono, S. (2001). Analisis Data. Depok: Fakultas Kesehatan Masyarakat Universitas Indonesia.

Indriani, I, dkk. (2001). AyahBunda. Buku Pegangan Untuk Pengasuhan Bayi.

Edisi Juli 2001. Jakarta: PT Grafika Multi Warna.

Machfoedz, I. (2008). Alat ukur Penelitian. Yogyakarta: Fitramaya.

Mutia (2009) "Faktor-faktor yang mempengaruhi ibu menyusui dengan

pemberian ASI Eksklusif di Wilayah UPTD Puskesmas Kelurahan Kotabaru kecamatan Bekasi Barat tahun 2009". Skripsi, Universitas Indonesia.

Notoatmodjo, S. (2003). Metodelogi Penelitian Kesehatan. Jakarta: Rineka Cipta.

Notoatmodjo, S. (2005). Promosi Kesehatan Teori dan Aplikasi. Jakarta: Rineka Cipta.

Notoatmodjo, S. (2007). Promosi kesehatan dan IImu Perilaku. Jakarta: Rineka Cipta.

Prawiroharjo, S. (2006). Pelayanan Kesehatan Meternal dan Neonatal. Jakarta: PT BP$\mathrm{SP}$

Roesli, U. (2000). Mengenal Asi Eksklusif Seri 1. Jakarta: Trubus Agriwidya.

Roesli, U. (2009). Panduan Praktis Menyusui. Jakarta: Pustaka Bunda

Sears, W dan Marthan, S. (2009). The baby Book Jilid 2. Jakarta: Indonesia

Setiati, S. (2011). Pedoman Penulisan Usulan Penelitian. Jakarta: InternaPublishing.

Septiana (2010) "Hubungan Antara Karakteristik Ibu Nifas Dengan Motivasi Memberikan ASI Pada Ibu Nifas Di Rumah Sakit Dr. S. Hardjolukito Yogyakarta". Skripsi, Universitas Respati Yogyakarta.

Shaleh, A. (2008). Psikologi: Suatu Pengantar Dalam Perseptik Islam. Jakarta: Kencana Prenada Media Group. 